Fisher, K. W. (1957). J. gen. Microbiol. 16, 120-135

\title{
The Role of the Krebs Gycle in Conjugation in Escherichia coli K-12
}

\author{
By K. W. FISHER \\ Department of Bacteriology, Postgraduate Medical School of London, \\ London, W. 12
}

SUMMARY: Zygote formation between strains of Escherichia coli K-12 is dependent on a supply of free energy made available by the oxidation of carbohydrate via the Krebs cycle reactions. The simultaneous addition of glucose and a dicarboxylic acid of the tricarboxylic acid cycle, or an immediate precursor, to mating cells markedly stimulates the number of zygotes formed. Reagents known to inhibit reactions of the Krebs cycle inhibit zygote formation. Evidence was obtained that synthesis of protein or either pentose or deoxypentose nucleic acid was not necessary for zygote formation.

Genetic recombination in Escherichia coli, strain K-12, was first demonstrated by the isolation of prototrophic clones from a mixture of two auxotrophic mutant strains having multiple and complementary nutritional requirements (Lederberg \& Tatum, 1946). When the parental strains were differentially marked by other characters not involved in prototroph formation (e.g. carbohydrate fermentation, and resistance to drugs such as streptomycin or sodium azide and to bacteriophages), genetic analysis showed that these unselected markers were linked to one another as well as to the selected, auxotrophic markers (Lederberg, 1947). Despite this continuity of linkage, however, the genetic data were inconsistent with a completely linear arrangement of the genes on a single chromosome (Newcombe \& Nyholm, 1950; Lederberg, Lederberg, Zinder \& Lively, 1951; Rothfels, 1952).

The differentiation of fertile Escherichia coli strains into two mating types, one of which acted as a genetic donor and the other as a recipient, was first described by Hayes (1952). It was later shown that the donor character, called $\mathbf{F}$ (for fertility), could be transferred to recipient cells independently of the usual genetic markers and with an efficiency of the order of $100 \%$ (Lederberg, Cavalli \& Lederberg, 1952; Cavalli, Lederberg \& Lederberg, 1953; Hayes, 1953a). Crosses between recipient $(\mathrm{F}-)$ strains were sterile; crosses between donor $(\mathbf{F}+)$ and recipient strains showed maximum fertility. Thus $\mathbf{F}$ appeared as a factor which controlled the ability to transfer genetic material as well as the direction of transfer.

In $\mathrm{F}+\times \mathrm{F}-$ crosses the maximum yield of recombinants is about $10^{-4}$ to $10^{-5}$ per $\mathbf{F}+$ cell. Two donor mutants were independently isolated from strain 58-161 $\mathrm{F}+$ which were about 1000 times more productive in crosses with the same F - strain (Cavalli, 1950; Hayes, 1953b). These mutants, which were unable to convert $\mathbf{F}$ - cells to the $\mathbf{F}+$ state, were called $\mathrm{Hfr}$ (high frequency of recombination).

Unlike transformation and transduction, transfer of genetic material from 
donor to recipient cell in Escherichia coli requires actual cellular contact and is, therefore, mediated by conjugation. The kinetics of this process in fluid media was first studied by Nelson (1951) who showed that it was analogous to a second-order reaction involving only single contacts between the participating cells. Hayes (1957) devised a method for studying the kinetics of zygote formation in $\mathbf{H f r} \times \mathbf{F}-$ systems. Samples of a mixture of the two parents were removed at intervals after mixing and treated with virulent phage to which only the Hfr (donor) cells were susceptible. The donor cells were thus rapidly killed so that only those $\mathbf{F}$ - recipient cells which had already been fertilized at the time of adding the phage (i.e. zygotes) could produce recombinants. Hayes had observed that when well-washed parental suspensions were plated together on minimal medium prepared with highly purified agar, no recombination occurred. The cross was normally productive, however, when the medium was supplemented with either asparagine or aspartic acid. In contrast, washed zygotes, which had already been formed in broth, produced the expected number of recombinants on the unsupplemented medium, which also supported the growth of recombinant prototrophs. It thus appeared that asparagine or aspartic acid were specifically required for zygote formation (Hayes, 1957). This paper describes an investigation into the physiological requirements for zygote formation which was initiated by these observations.

\section{Definition of terms}

(1) Zygote. This connotes a recipient $(\mathbf{F}-)$ cell which has received a chromosomal contribution from a donor $(\mathbf{H f r}$ or $\mathbf{F}+)$ cell. Only a proportion of zygotes will yield recombinants of any given genetic constitution.

(2) Recombination rate. This is expressed as the number of recombinants of any given class per $100 \mathrm{~F}-$ cells initially present.

\section{METHODS}

Organisms. Strain 58-161 F + is a methionine-requiring $(\mathbf{M}-)$ Escherichia coli K-12 mutant sensitive to streptomycin ( $\left.\mathrm{S}^{\mathrm{s}}\right)$ and sodium azide $\left(\mathbf{A z ^ { \mathrm { s } }}\right)$. This strain ferments lactose and maltose $(\mathrm{Lac}+, \mathrm{Mal}+)$, and is sensitive to coliphage $\mathrm{T}_{6}\left(\mathrm{~V}_{6}\right)$.

Strain $58-161 \mathrm{Hfr}$, isolated by Hayes $(1953 b)$ carries the same nutritional markers as 58-161 F+. It is, however, resistant to streptomycin (Sr) $\left(250 \mu \mathrm{g} . / \mathrm{ml}\right.$.) and to sodium azide $\left(\mathbf{A z}^{\mathrm{r}}\right)(\mathrm{M} / 500)$.

Strain W-1 F - (Lederberg \& Lederberg, 1952) requires threonine, leucine and thiamine $\left(\mathrm{B}_{1}\right)$ for growth $\left(\mathrm{TLB}_{1}-\right)$. Its sugar fermentation markers are $\mathrm{Lac}_{\mathbf{1}}$ - and $\mathrm{Mal}_{1}$ - and the variant used in this work was $\mathrm{Sr}^{\mathbf{r}}$ and $\mathbf{V}_{\mathbf{6}}^{\mathbf{r}}$.

Strain W-677 F - (Lederberg, 1950) also requires threonine, leucine and thiamine for growth $\left(\mathrm{TLB}_{1}-\right)$. The strain is sensitive to streptomycin and resistant to $\mathrm{M} / 500$ sodium azide $\left(\mathrm{Az}^{\mathrm{r}}\right)$.

Buffer. An aqueous solution containing $0.4 \%(\mathrm{w} / \mathrm{v}) \mathrm{NaCl}, 0.02 \%(\mathrm{w} / \mathrm{v})$ $\mathrm{MgSO}_{4} \cdot 7 \mathrm{H}_{2} \mathrm{O}$ and $\mathrm{M} / 20 \mathrm{KH}_{2} \mathrm{PO}_{4}$, the $\mathrm{pH}$ value required being obtained with $0 \cdot 2 \mathrm{M}-\mathrm{NaOH}$. 
Minimal agar was as described by Tatum \& Lederberg (1947) except that asparagine was omitted from the medium which was solidified with $2 \%(\mathrm{w} / \mathrm{v})$ agar and supplemented with $0.2 \%(\mathrm{w} / \mathrm{v}) \mathrm{D}$-glucose and $5 \mu \mathrm{g}$. thiamine $/ \mathrm{ml}$. (medium $\mathrm{MAB}_{1}$ ). The agar powder was washed with distilled water for 2 days before use.

Nutrient broth was a beef digest broth routinely used in this department.

Chemical reagents. With two exceptions, the reagents were supplied by British Drug Houses Ltd and, except for DL-malic acid, were all of A.R. quality. Sodium monofluoroacetate was very kindly provided by $\operatorname{Dr}$ S. R. Elsden and the L-aspartic acid was obtained from L. Light and Co., Colnbrook. Before use all stock solutions of the acids were adjusted to $\mathrm{pH} 7$ with sodium hydroxide.

Coliphage $T_{6}$ suspensions. Cultures of Escherichia coli strain B, growing logarithmically in nutrient broth, were infected with phage $\mathrm{T}_{6}$ at low multiplicity. The mixture was aerated until lysis occurred. Phage $\mathrm{T}_{6}$ propagated in this manner normally yielded $10^{10}$ to $10^{11}$ plaque-forming particles $/ \mathrm{ml}$. Residual $E$. coli cells were killed by heating at $56^{\circ}-58^{\circ}$ for $30 \mathrm{~min}$.

Experiments to test the conditions necessary for zygote formation, unless otherwise specified, were carried out in $4 \times \frac{5}{8}$ in. test tubes sealed with rubber bungs. Between experiments the tubes were stored in chromic-sulphuric acid and the bungs in distilled water. Before use, both tubes and bungs were washed several times in distilled water and then autoclaved.

\section{Basic experimental procedure}

Strains were stored on Dorset egg slopes at $4^{\circ}$. Cultures for use were propagated from such stocks by overnight growth in nutrient broth, without aeration, at $37^{\circ}$. The following morning 1 vol. of each parental culture was diluted into $10 \mathrm{vol}$. of fresh broth at $37^{\circ}$ and incubated at this temperature in screw-cap bottles for $105 \mathrm{~min}$. on an inclined turntable rotating at 33 r.p.m. The volume of the bottles was such that an adequate supply of oxygen was available to the organisms during growth. At the end of the incubation period the cultures were washed separately with three changes of buffer $(\mathrm{pH} \mathrm{7 \cdot 2})$. The yield of organisms from $\mathbf{2 . 5} \mathrm{ml}$. of culture of each parent strain was then mixed and centrifuged. The supernatant fluid was removed and the mixed deposit resuspended in $5 \mathrm{ml}$. of warmed test medium and aerated at $37^{\circ}$ for $30 \mathrm{~min}$. on the turntable. At the end of this period $1 \mathrm{ml}$. of the mixture was added to an equal volume of coliphage $T_{6}$ suspension and aerated for $20 \mathrm{~min}$. at $37^{\circ}$. This procedure destroyed the $\mathrm{Hfr}$ or $\mathrm{F}+$ parent (since both are sensitive to $T_{6}$ ) and thus stopped further zygote formation. Such a treated mixture, in which only zygotes and $\mathbf{F}$ - cells remained viable, will be referred to as a zygote suspension.

\section{Plating and counting techniques}

Detection of zygotes. In the $\mathrm{Hfr} \times \mathrm{F}-$ and $\mathrm{F}+\times \mathrm{F}-$ crosses used, prototrophs arise on $\mathrm{MAB}_{1}$ as a result of selection for that recombinant class in which the closely linked genes $\mathbf{T}+\mathbf{L}+$ inherited from the donor parent replace 
the $\mathbf{T}-\mathbf{L}-$ genes determining the auxotrophy of the recipient $(\mathbf{F}-$ ) ceils. Since zygotes of the same genetic constitution may yield different recombinant classes, and since not all zygotes do yield recombinants (see Wollman, Jacob \& Hayes, 1956), it is clear that the total number of zygotes cannot be directly estimated. In order to study zygote formation, therefore, the assumption was made that the number of zygotes is directly proportional to the number of $\mathbf{T}+\mathbf{L}+$ prototrophic recombinants formed.

The number of $\mathbf{T}+\mathbf{L}+$ recombinants was determined by diluting the zygote suspension by a factor of $2 \times 10^{-4}$ in buffer $(\mathrm{pH} \mathrm{7 \cdot 2)}$. Samples $(0 \cdot 01 \mathrm{ml}$.) of the diluted suspension were then plated in triplicate on medium $\mathbf{M A B}_{1}$, by using a standardized, welded platinum loop. The number of prototrophic colonies was counted after $18 \mathrm{hr}$. of incubation at $37^{\circ}$.

Total viable counts. These were carried out on the parental suspensions immediately before they were mixed. The suspension was diluted $10^{-5}$ in buffer $(\mathrm{pH} \mathrm{7.2)}$ and $0.01 \mathrm{ml}$. volumes were plated in triplicate on nutrient agar with a standardized platinum loop. Colonies were counted after $18 \mathrm{hr}$, of incubation at $30^{\circ}$.

\section{RESULTS}

\section{Zygote formation on solid media}

Washed suspensions of strains 58-161 Hfr and W-1 F - were plated together on:

(1) minimal agar + thiamine prepared with unwashed agar $\left(\mathbf{M A B}_{1}\right)$;

(2) minimal agar + thiamine prepared with agar specially washed with sodium hypochlorite solution ( $5 \%$ available chlorine), tap and distilled water, and acetone $\left(\mathrm{WMAB}_{1}\right)$;

(3) a similar minimal medium supplemented with thiamine and solidified with silica gel in place of agar $\left(\mathrm{MSB}_{1}\right)$;

(4) the same media supplemented with $0.025 \%$ sodium L-aspartate.

Prototrophs were counted after $18 \mathrm{hr}$. of incubation at $37^{\circ}$.

\section{Table 1. The formation of prototrophs on solid media}

Parent suspensions of 58-161 Hfr and W-1 F - were grown aerobically in nutrient broth,

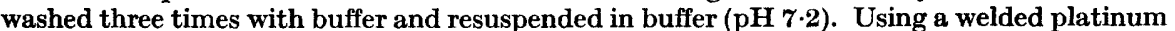
loop, triplicate $0.01 \mathrm{ml}$. samples of each suspension were spread over the surface of $2.5 \mathrm{~cm}$. plates of media. Counts were read after incubation at $37^{\circ}$ for $18 \mathrm{hr}$.

\begin{tabular}{lc}
\multicolumn{1}{c}{ Media* } & $\begin{array}{c}\text { Prototrophs } \\
\text { (no. 1 plate) }\end{array}$ \\
MAB $_{1}$ & $>500$ \\
WMAB $_{1}$ & 56 \\
WMAB $_{1}+0.025 \%$ sodium L-aspartate & $>500$ \\
MSB $_{1}$ & 0 \\
MSB $_{1}+0.025 \%$ sodium L-aspartate & $>500$
\end{tabular}

* $\mathrm{MAB}_{1}=$ minimal agar + glucose + thiamine. $\mathrm{WMAB}_{1}=$ minimal agar + glucose + thiamine, solidified with the specially washed agar (see text). MSB $_{1}=$ minimal medium + glucose + thiamine, solidified with silica gel.

The results (Table 1) showed that purified agar or silica gel lacked some unknown substance which was essential for the formation of prototrophic 
recombinants. This apparent deficiency was remedied by the addition of L-aspartic acid. Aqueous extracts of powdered agar were prepared and added to $\mathrm{WMAB}_{1}$ but prototrophs were not formed even when concentrated (15 times) extracts were added. The same extracts were examined by paper chromatography for the presence of amino acids. Butanol/acetic acid/water $(40: 10: 50)$ was used as the developing agent and the chromatograms were sprayed with $0.1 \%$ ninhydrin in water-saturated $n$-butanol. No amino acids were detected. The extracts were not examined for substances other than amino acids.

\section{Zygote formation in fuid media}

The results obtained by supplementing washed minimal agar with aspartic acid suggested that this substance was necessary for zygote formation. Zygotes which had been preformed in nutrient broth yielded recombinants with the same efficiency on medium $\mathrm{WMAB}_{1}$ as on medium $\mathrm{MAB}_{1}$. The role of aspartic acid in zygote formation in fluid media was therefore examined. In several experiments, the recombination rate of an $\mathrm{Hfr} \times \mathrm{F}-$ mixture in unsupplemented buffer at $\mathrm{pH} \mathbf{7 \cdot 2}$ was consistently less than $3 \%$ of that observed in nutrient broth when samples were compared at $30 \mathrm{~min}$. after mixing. A low rate was also observed when a mineral salt solution similar to that used in the preparation of minimal agar was substituted for the buffer. When the buffer was supplemented with aspartic acid alone, only a very small rise in the recombination rate was detected. Similarly, the addition to the buffer of glucose alone elicited only a slight increase in the rate. The simultaneous addition of both glucose and aspartate, however, yielded a number of $\mathbf{T}+\mathbf{L}+$ recombinants equal to or exceeding the number obtained in nutrient broth. The results of these experiments are summarized in Fig. 1.

It was found that the recombination rate varied directly with the concentration of aspartic acid within the range 1-80 $\mu \mathrm{g} . / \mathrm{ml}$. Concentrations below $1 \mu \mathrm{g} . / \mathrm{ml}$. had no detectable effect on the recombination rate, whilst those between $80 \mu \mathrm{g}$. and $200 \mu \mathrm{g}$. $/ \mathrm{ml}$. did not produce a further increase in the number of zygotes formed (see Fig. 2). Concentrations of aspartic acid greater than $200 \mu \mathrm{g} . / \mathrm{ml}$. inhibited zygote formation.

\section{The role of aspartic acid in zygote formation}

It was thus established that aspartic acid and glucose are required for zygote formation. How do these substances act? Three possible modes of action of the aspartic acid were considered: (1) its possible importance as an essential intermediate of a biosynthetic pathway; (2) as an adsorption co-factor enabling the parent cells to make effective contact; (3) as a means of entry to the Krebs cycle for a $\mathrm{C}_{4}$ fragment which would stimulate the oxidation of $\mathrm{C}_{2}$ fragments (derived from glucose) via the tricarboxylic acid cycle.

The demonstration in Escherichia coli of the reversible reaction aspartic acid $\rightleftharpoons$ fumaric acid + ammonia (Quastel \& Woolf, 1926), as well as the possession by this organism of a glutamic-aspartic transaminase (Lichstein \& Cohen, 1944) rendered the first possibility feasible since these two systems, linked 


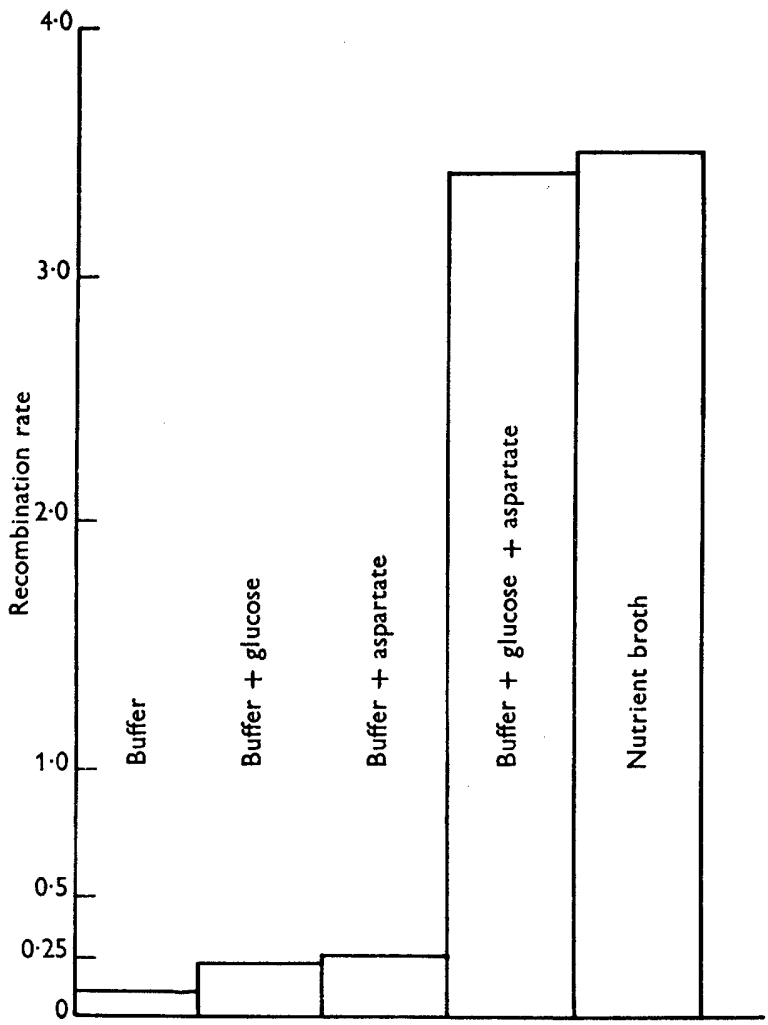

Fig. 1. Zygote formation in fluid media. Parent suspensions (58-161 Hfr and W-1 F-) were grown aerobically in broth, washed three times in buffer (pH 7-2), mixed and resuspended in the media shown. The buffer (pH 7.2) was supplemented as indicated with $20 \mu \mathrm{mole}$ glucose $/ \mathrm{ml}$. and $200 \mu \mathrm{g}$ sodium $\mathrm{L}$-aspartate $/ \mathrm{ml}$. After incubating the mixture of parent cells for $30 \mathrm{~min}$. the number of zygotes formed in each test medium was estimated.

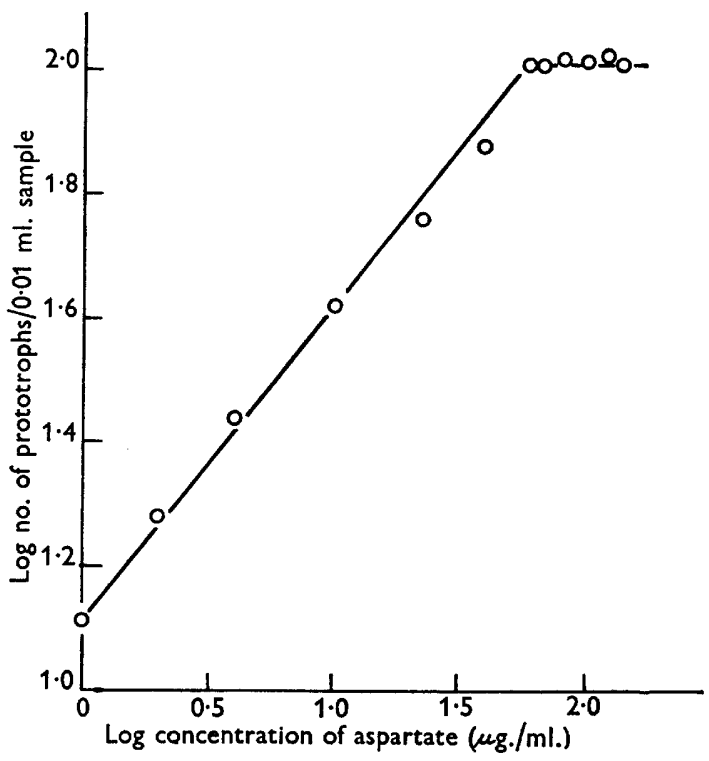

Fig. 2. The variation of recombination rate with the concentration of sodium L-aspartate. Parent cells (58-161 Hfr and W-1 F-) were washed with buffer ( $\mathrm{pH} \mathrm{7 \cdot 2)}$ and mated for $30 \mathrm{~min}$. in buffer ( $\mathrm{pH} \mathrm{7 \cdot 2)-glucose}(20 \mu \mathrm{mole} / \mathrm{ml}$. $)$-aspartate. The number of zygotes formed at the end of this period was determined. 
together, would enable $\mathrm{NH}_{4}^{+}$ions to be incorporated into the organic nitrogen of the cell. It was, however, ruled out by finding that nitrogen in the form of ammonium ions ( $50 \mu \mathrm{g} . \mathrm{NH}_{\mathbf{3}}-\mathrm{N} / \mathrm{ml}$.) did not stimulate zygote formation either in the presence or absence of glucose. Since the activity of $\mathrm{L}$-aspartic acid can be reproduced by other substances having quite different stereochemical configurations, as the next section will show, it is unlikely that L-aspartic acid acts as an adsorption co-factor.

\section{The effects on zygote formation in fluid media of replacing L-aspartic acid by other substances}

A search was made for substances capable of replacing aspartic acid in promoting zygote formation in the presence of glucose. Most of the substances tested were substituted or unsubstituted dicarboxylic acids. They fell into three groups according to the effects they produced: (i) those having a stimulatory effect similar to that of L-aspartic acid; (ii) those without effect; (iii) substances inhibiting zygote formation.

The first group comprised DL-glutamic acid, succinic acid, fumaric acid and DL-malic acid. Of these, only DL-glutamic acid behaved in the same way as L-aspartic acid with regard to zygnte formation. Succinic, fumaric and DL-malic acids did not raise the recombination rate when added to buffer +

\section{Table 2. The effect of $\mathrm{pH}$ value on the activity of succinic, fumaric and malic acids in zygote formation}

Parent suspensions were prepared in the standard manner (see Methods) and mated in the media show below. Substrate concentrations, unless specified otherwise, were the same in all experiments. Glucose: $20 \mu \mathrm{mole} / \mathrm{ml}$; the acids (as sodium salts) were used at a concentration equivalent to $80 \mu \mathrm{g}$. free acid $/ \mathrm{ml}$.

$\quad$ Parents mated in
Buffer
Buffer + glucose
Buffer + glucose + aspartate
Buffer + glucose + succinate
Buffer + glucose + fumarate
Buffer + glucose + malate

Viable counts of parent suspensions:

\begin{tabular}{cc} 
Recombination rate at \\
\hline pH 7.2 & pH 6.5 \\
$0 \cdot 12$ & 0.36 \\
0.36 & $1 \cdot 0$ \\
$2 \cdot 8$ & $7 \cdot 1$ \\
0.62 & $3 \cdot 0$ \\
0.26 & $2 \cdot 4$ \\
0.29 & $2 \cdot 8$
\end{tabular}

58-161 Hfr $=3.4 \times 10^{8}$ organisms $/ \mathrm{ml}$. W-1 F $-=2.9 \times 10^{8} \mathrm{organisms} / \mathrm{ml}$.

glucose at $\mathrm{pH} 7 \cdot 2$ in the same molar concentrations as L-aspartic and DLglutamic acids. However, when these substances were tested in buffer + glucose at $\mathrm{pH} \mathrm{6.5} \mathrm{they} \mathrm{showed} \mathrm{considerable} \mathrm{activity} \mathrm{(Table} \mathrm{2)} \mathrm{which} \mathrm{was} \mathrm{further}$ accentuated at pH 5.8 (Table 6). From the results given in Table 6 it can be seen that in media buffered at $\mathrm{pH} 5.8$ succinic, fumaric, DL-malic, L-aspartic and DL-glutamic acids stimulated the recombination rate to the same extent.

DL- $\alpha$-Alanine, DL-tyrosine, DL-proline, DL-phenylalanine, oxalic, pimelic and adipic acids had no effect on the recombination rate. The fact that the latter substances were inactive suggested that the activity shown by the members 
of the first group was not due solely to their dicarboxylic nature. In addition, the inactivity of the amino acids does not support the hypothesis that the importance of $\mathrm{L}$-aspartic acid is due to the utilization of the $\alpha$-amino nitrogen during the formation of a zygote.

Only malonic acid was observed to inhibit zygote formation. Cells of each parental strain (58-161 Hfr and W-1 F-) were grown and washed as previously described and then mixed in various media with and without malonic

\section{Table 3. The effect of malonate on zygote formation}

Suspensions of parent cells were prepared in the usual manner and mated in the media shown in the table which were buffered at pH 6.5. The concentration of sodium malonate used was equivalent to $6.5 \mathrm{mg}$. free acid $/ \mathrm{ml}$.

$\begin{array}{cc}\overbrace{\text { Without malonate }}^{2} \text { With malonate } \\ 0 \cdot 36 & 0 \\ 1 \cdot 0 & 0 \cdot 32 \\ 7 \cdot 1 & 3 \cdot 0 \\ 3 \cdot 0 & 0 \cdot 36 \\ 2 \cdot 5 & 0.59 \\ 2 \cdot 8 & 0.65\end{array}$

Viable counts on parent suspensions :

58-161 Hfr $=3.4 \times 10^{8}$ organisms $/ \mathrm{ml}$. W-1 $\mathrm{F}-=2.9 \times 10^{8}$ organisms $/ \mathrm{ml}$.

acid. The results (Table 3 ) showed that malonic acid partially inhibited zygote formation. The recombination rate was reduced to a quarter or less of the rate observed in the absence of the inhibitor except in the case of aspartic acid.

It was found that acetate could replace glucose for the formation of zygotes when the mixture was buffered to $\mathrm{pH} 6 \cdot 5$. At higher $\mathrm{pH}$ values no evidence of replacement could be found, probably due to the non-penetration of the acetate ions. At pH 5.8 the parent cells were killed when suspended in buffer + acetate. It can be seen from Table 4 that the rate of recombination

\section{Table 4. $A$ comparison of the effects of glucose and of acetate on zygote formation}

Parent suspensions were prepared in the usual way and mated in the media shown, buffered at $\mathrm{pH} \mathrm{6.5}$. The concentration of sodium acetate was $40 \mu \mathrm{mole} / \mathrm{ml}$, other substrates were used at concentrations given in Table 2.

$\begin{array}{lcc}\text { Parents mated in } & \text { With glucose } & \text { With acetate } \\ \text { Buffer } & \mathbf{0 \cdot 2 1} & \mathbf{1 \cdot 6} \\ \text { Buffer + aspartate } & \mathbf{6 \cdot 9} & \mathbf{3 \cdot 7} \\ \text { Buffer + succinate } & \mathbf{3 \cdot 0} & \mathbf{3 \cdot 5} \\ \text { Buffer + fumarate } & \mathbf{3 \cdot 2} & \mathbf{3 \cdot 2} \\ \text { Buffer + malate } & \mathbf{2 \cdot 5} & \mathbf{3 \cdot 6}\end{array}$

Viable counts on parental suspensions:

58-161 Hfr $=3.0 \times 10^{8} \mathrm{organisms} / \mathrm{ml}$. W-1 F $-=2.9 \times 10^{8} \mathrm{organisms} / \mathrm{ml}$. 
in buffer + acetate alone was considerably higher than in buffer + glucose alone. This observation may possibly be due to the ability of Escherichia coli to couple two molecules of acetate to form succinate (Ajl \& Kamen, 1950).

\section{Zygote formation under anaerobic conditions}

The tricarboxylic acid cycle is a catalytic pathway for the oxidation of ' $\mathrm{C}_{2}$ fragments'. Its continued operation is dependent upon an adequate supply of oxygen which is utilized as the terminal hydrogen acceptor. If, as these experiments suggest, the formation of zygotes is dependent on the functioning of the Krebs cycle, then inhibition or stimulation of these reactions should also affect the recombination rate. The ability to form zygotes under anaerobic conditions was assessed as follows. The parent strains $\left(58-161 \mathrm{HfrV}_{6}^{\mathrm{s}}\right.$ and $\mathbf{W}-1 \mathbf{F}-\mathbf{V}_{\mathbf{6}}^{\mathrm{r}}$ ) were grown aerobically in nutrient broth, washed separately with three changes of buffer ( $\mathrm{pH} \mathrm{6.5)}$ and resuspended in buffer at the same pH value. Samples of each parental suspension were transferred separately to different compartments of a series of Thunberg tubes each containing a different test medium (see Table 5). The tubes were flushed with nitrogen, evacuated and sealed. After warming to $37^{\circ}$ the parental suspensions were mixed and rotated at $37^{\circ}$ for $30 \mathrm{~min}$. In a parallel aerobic experiment samples of the same parent suspensions and test media were used. The number of zygotes formed was estimated in the usual manner at the end of the $\mathbf{3 0}$ min. period. The experimental results given in Table 5 show clearly that zygotes were not formed at a significant rate under anaerobic conditions.

\section{Table 5. Comparison of the efficiency of zygote formation in various media under aerobic and anaerobic conditions}

Parent suspensions were grown and washed aerobically, and mixed under aerobic and anaerobic conditions in the test media shown, which were buffered at $\mathrm{pH} \mathrm{6.5}$. The substrate concentrations shown in Table 2 were used.

Recombination rate

$\quad$ Parents mated in
Buffer + glucose
Buffer + glucose + aspartate
Buffer + glucose + succinate
Buffer + glucose + fumarate
Buffer + glucose + malate
Buffer + glucose + glutamate

$\begin{array}{cc}\text { Aerobic } & \text { Anaerobic } \\ \mathbf{0 . 2 5} & 0 \\ \mathbf{5 . 7} & 0.04 \\ \mathbf{3 . 7} & 0.07 \\ \mathbf{3 . 7} & 0.04 \\ \mathbf{3 . 4} & \mathbf{0 . 1 4} \\ \mathbf{6 . 0} & \mathbf{0 . 2 2}\end{array}$

Viable counts on parental suspensions:

58-161 Hfr $=2.7 \times 10^{8}$ organisms $/ \mathrm{ml}$. W-1 F- $=2.8 \times 10^{8}$ organisms $/ \mathrm{ml}$.

\section{The effect of metabolic inhibitors on zygote formation}

Fluoroacetic acid. Fluoroacetic acid acts as a poison by first being converted to fluorocitric acid which then competitively inhibits the metabolism of citric acid by the tricarboxylic acid cycle (Buffa \& Peters, 1949; Liébecq \& Peters, 1949; Lotspeich, Peters \& Wilson, 1952). The ability of this inhibitor to stop zygote formation was accordingly investigated. As much as $75 \%$ inhibition 
of zygote formation was achieved by using $10^{-3} \mathrm{M}$-sodium monofluoroacetate. The fluoroacetate did not inhibit zygote formation in buffer + glucose + dicarboxylic acid at $\mathrm{pH}$ values higher than $\mathrm{pH} 6$. The concentration of glucose was important. The concentration normally used $(20 \mu \mathrm{mole} / \mathrm{ml}$. $)$ had to be decreased to $2 \mu \mathrm{mole} / \mathrm{ml}$. before definite inhibition of zygote formation was detected. This figure of $2 \mu \mathrm{mole} / \mathrm{ml}$. is near the lowest concentration of glucose capable of supporting zygote formation and growth of the subsequent prototrophic clones on a minimal agar plate.

\section{Table 6. The effect of sodium monofluoroacetate on zygote formation}

Suspensions of parent cells were prepared by the standard procedure and mated under the conditions shown. The concentration of glucose in the media (buffered at pH 5.8) was decreased to $2 \mu \mathrm{mole} / \mathrm{ml}$. Sodium monofluoroacetate was used at $10^{-3} \mathrm{M}$.

Recombination rate

$\begin{array}{cc}\begin{array}{c}\text { With } \\ \text { fluoroacetate }\end{array} & \begin{array}{c}\text { Without } \\ \text { fluoroacetate }\end{array} \\ 0 \cdot 12 & 0 \cdot 79 \\ 0 \cdot 31 & 1 \cdot 0 \\ 2 \cdot 9 & 6 \cdot 4 \\ 3 \cdot 4 & 6 \cdot 4 \\ 2 \cdot 8 & 6 \cdot 0 \\ 2 \cdot 1 & 6 \cdot 1 \\ 2 \cdot 2 & 6 \cdot 7\end{array}$

Viable counts on parent suspensions :

58-161 Hfr $=2 \cdot 2 \times 10^{8}$ organisms $/ \mathrm{ml}$. W-1 F $-=2 \cdot 4 \times 10^{8}$ organisms $/ \mathrm{ml}$.

This effect of sodium monofluoroacetate affords further evidence that the tricarboxylic acid cycle is involved in zygote formation but it is not conclusive because of the incompleteness of the effect and also, as Elsden (1954) has pointed out, because fluoroacetate may possibly inhibit any reaction in which a $\mathrm{C}_{2}$ condensation with a $\mathrm{C}_{x}$ fragment is involved.

Sodium cyanide. Cyanide is known to inhibit the oxidation of reduced cytochrome ' $c$ ' by cytochrome oxidase. The oxidation of succinate to fumarate, and of malate to oxalacetate, both oxidative steps of the Krebs cycle, are linked to a cytochrome system either directly or through the intermediary of diphosphopyridine nucleotide (DPN). Table 7 shows that zygote formation between auxotrophic parent strains of Escherichia coli K-12 was almost completely inhibited in the presence of $\mathrm{M} / 500 \mathrm{NaCN}$ at $\mathrm{pH} 6 \cdot 5$. This result supports the hypothesis that the efficient operation of the Krebs cycle is necessary for the formation of zygotes, although it must still be borne in mind that all other reactions dependent on terminal oxidations by means of cytochrome systems will also be affected by this particular inhibitor.

Dinitrophenol. The functions of the Krebs cycle are twofold. One is to provide the cell with an adequate supply of intermediates which can be further modified to provide amino acids (Roberts et al. 1953; Abelson et al. 1953). The other is the release of energy, associated with hydrogen transport by the cellular cytochromes and its final oxidation by molecular oxygen. This 


\section{Table 7. The effect of sodium cyanide on zygote formation}

Washed parent suspensions were mated in the media shown (buffered at $\mathrm{pH} \mathrm{6.5)}$, the substrate concentrations used were the same as shown in Table 2. The concentration of sodium cyanide used was $2 \times 10^{-3} M$.

$\quad$ Parents mated in
Buffer
Buffer + glucose
Buffer + glucose + aspartate
Buffer + glucose + succinate
Buffer + glucose + fumarate
Buffer + glucose + malate

Viable counts on parental suspensions:

$\begin{array}{cc}\begin{array}{c}\text { With } \\ \text { cyanide }\end{array} & \begin{array}{c}\text { Without } \\ \text { cyanide }\end{array} \\ 0 & 0.5 \\ - & 1.5 \\ 0.2 & 7 \cdot 2 \\ 0.5 & 3.2 \\ 0.2 & 3.0 \\ 0.3 & 3.5\end{array}$

58-161 Hfr $=3.3 \times 10^{8}$ organisms $/ \mathrm{ml}$. W-1 $\mathrm{F}-=2.9 \times 10^{8} \mathrm{organisms} / \mathrm{ml}$.

free energy is made available to cells by the formation of high energy bonds associated with adenosine triphosphate (ATP). ATP is able to donate its terminal phosphate group together with the free energy associated with it to certain classes of substances, forming phosphorylated derivatives. Such phosphorylated substances, having a higher free energy content, can take part in reactions which, on thermodynamic grounds, would be denied to the corresponding non-phosphorylated substance. In this way respiration is coupled with synthesis. It has been demonstrated that certain substances can prevent the accumulation of ATP. Among these are gramicidin, atebrin and 2:4-dinitrophenol. The work of Loomis \& Lipmann (1948) and especially Teply (1949) has shown that 2:4-dinitrophenol acts as an uncoupling agent (i.e. disconnecting synthesis from respiration) by degrading ATP to inorganic phosphate. Table 8 shows the results of crosses between 58-161 Hfr and W-1

\section{Table 8. The effect of 2:4-dinitrophenol (DNP) on zygote formation}

The cell suspensions used in the particular experiment reported here were the same as those used for the experiment reported in Table 7. Substrate concentrations employed were also the same. Final concentration of $2: 4$-dinitrophenol was $10^{-3} \mathrm{M}$.

$\quad$ Parents mated in
Buffer
Buffer + glucose
Buffer + glucose + aspartate
Buffer + glucose + succinate
Buffer + glucose + fumarate
Buffer + glucose + malate

Recombination rate

$\begin{array}{cc}\text { With DNP } & \text { Without DNP } \\ 0 & 0.5 \\ 0.07 & 1.5 \\ 0.31 & 7 \cdot 2 \\ 0.14 & 3 \cdot 2 \\ 0.17 & 3 \cdot 0 \\ 0.17 & 3.5\end{array}$

Viable counts on parental suspensions :

58-161 Hfr $=3.3 \times 10^{8}$ organisms $/ \mathrm{ml}$. W-1 F $-=2 \cdot 9 \times 10^{8}$ organisms $/ \mathrm{ml}$.

$\mathrm{F}$ - in the presence of $10^{-3} \mathrm{M}-2: 4$-dinitrophenol. It can be seen that this substance prevented zygote formation. Thus one may conclude that the process of zygote formation is endergonic. 
In connexion with the use of inhibitors it was established that $10^{-3} \mathrm{M}$ 2:4-dinitrophenol, $2 \times 10^{-3} \mathrm{M}-\mathrm{NaCN}$ and $10^{-3} \mathrm{M}$-sodium monofluoroacetate had no detectable effect on the viability of the parental suspensions throughout the experimental period.

Chloramphenicol. Wisseman et al.'(1954) demonstrated the specific inhibition of protein synthesis in Escherichia coli by growth inhibitory levels of chloramphenicol. The inhibition was complete within $10 \mathrm{~min}$. of addition of the antibiotic to the cells. Table 9 shows the effect of chloramphenicol on zygote formation; the recombination rate was unaltered by $10 \mu \mathrm{g}$. chloramphenicol $/ \mathrm{ml}$. Growth of the donor strain was prevented by $5 \mu \mathrm{g}$. chloramphenicol $/ \mathrm{ml}$. These results suggest that protein synthesis is not specifically associated with zygote formation.

\section{Table 9. The effect of growth inhibitory concentrations of chloramphenicol and 8-azaguanine on zygote formation in Escherichia coli}

Washed parent suspensions of strains 58-161 Hfr and W-I F - were mated under the conditions shown. The media, buffered at $\mathrm{pH} \mathrm{6.5,} \mathrm{contained} \mathrm{the} \mathrm{same} \mathrm{substrate} \mathrm{con-}$ centrations as shown in Table 2 . The concentration of chloramphenicol used was $10 \mu \mathrm{g} . / \mathrm{ml}$. and, where indicated, $200 \mu \mathrm{g} .8$-azaguanine $/ \mathrm{ml}$. The number of zygotes formed was estimated after $30 \mathrm{~min}$. incubation at $37^{\circ}$ in the usual manner.

Parents mated in

\section{Recombination}

rate

Buffer + glucose + aspartate

$6 \cdot 3$

$6 \cdot 5$

$6 \cdot 3$

$7 \cdot 5$

$7 \cdot 0$

$7 \cdot 1$

Viable counts on parental suspensions:

$58-161 \mathrm{Hfr}=2.0 \times 10^{8}$ organisms $/ \mathrm{ml}$. W- $\mathrm{F}-=1.6 \times 10^{8}$ organisms $/ \mathrm{mI}$.

8-Azaguanine. Inhibition of nucleic acid synthesis has been achieved using a variety of inhibitors, among them ultraviolet light (Kelner, 1953), nitrogen mustard and 8-azaguanine (Skipper et al. 1951). 8-Azaguanine is non-specific in that it inhibits the synthesis of both pentose and deoxypentose nucleic acids. 8-Azaguanine at $200 \mu \mathrm{g}$. $/ \mathrm{ml}$. inhibited growth of the donor parent (58-161 Hfr) in fluid minimal medium supplemented with glucose and methionine; this concentration, however, did not affect the recombination rate either in buffer + glucose + aspartate $(\mathrm{pH} 6 \cdot 5)$ or in nutrient broth (Table 9).

It therefore seems unlikely that synthesis of either kind of nucleic acid is essential to zygote formation.

\section{Requirements for zygote formation between 58-161 $F+$ and $W-1 F-$}

Some of the experiments reported in the previous sections were repeated with the strains 58-161 F+ and W-1 F-. Experiments with an $\mathbf{F}+\times \mathbf{F}-$ system demand some small alterations of technique. Since the recombination rate is some 1000 times lower than in $\mathrm{Hfr} \times \mathrm{F}$ - crosses the zygote suspension must be plated relatively undiluted, so that the nutrient broth in which 
phage $T_{6}$ is suspended, together with the unabsorbed phage, must be removed by washing the cells with two changes of buffer after treatment with coliphage. The results observed (Table 10) paralleled those found with the equivalent Hfr $\times \mathbf{F}-$ cross, i.e. an energy source (glucose) was required together with aspartic acid, which could be replaced with succinic acid, fumaric acid or malic acid. 2,4-Dinitrophenol inhibited zygote formation.

\section{Table 10. Zygote formation by strains 58-161 $F+V_{6}^{\mathrm{s}}$ and $W-1 F-V_{6}^{\mathrm{r}}$}

Parental cell suspensions were prepared by washing aerobically grown cells with buffer (pH 7.2). The cells were mixed in the test media shown (pH 6.2) and incubated aerobically for 30 min. at $37^{\circ}$. The number of zygotes formed was estimated by treatment of the sample with phage $T_{6}$, washing the cells twice with buffer and resuspending to the original volume before plating on minimal agar + thiamine + glucose.

\begin{tabular}{|c|c|}
\hline Parents mated & $\begin{array}{l}\text { o. of } T+\mathbf{L}+ \\
\text { combinants per } \\
11 \text { ml. plated }\end{array}$ \\
\hline Buffer & 20 \\
\hline Buffer + glucose & 49 \\
\hline Buffer + glucose + aspartate & 334 \\
\hline Buffer + glucose + succinate & 160 \\
\hline Buffer + glucose + fumarate & 148 \\
\hline Buffer + glucose + malate & 179 \\
\hline Buffer + glucose $+10^{-3} \mathrm{M}-\mathrm{DNP} *$ & $\mathbf{5}$ \\
\hline Buffer + glucose + aspartate $+10^{-3} \mathrm{M}-\mathrm{DNI}$ & NP 10 \\
\hline
\end{tabular}

\section{DISCUSSION}

It will be convenient to repeat the three suggestions made previously to account for the action of L-aspartic acid during zygote formation. These were: (i) its possible importance as an essential intermediate of a biosynthetic pathway; (ii) its action as an adsorption co-factor necessary for the effective union of donor and recipient cells; (iii) its functioning as a means of entry to the Krebs cycle for $\mathrm{C}_{4}$ fragments capable of increasing the rate of oxidation of $\mathrm{C}_{2}$ fragments derived from glucose.

Of the amino acids tested for their effect on zygote formation only glutamic acid showed the same effect as aspartic acid. Ammonium ion had no effect on the recombination rate under any conditions tested, a fact which makes it extremely unlikely that aspartate influences recombination through transamination reactions. Moreover, substances not containing $\alpha$-amino-nitrogen can stimulate the recombination rate. Furthermore, it was shown that chloramphenicol, which is known specifically to inhibit protein synthesis in Escherichia coli (Wisseman et al. 1954), does not prevent zygote formation when used at concentrations which rapidly prevent cell proliferation. Protein synthesis seems therefore not essential for zygote formation.

Reichard (1954) showed that aspartic acid is a precursor of ureidosuccinic acid and ultimately of orotic acid which possesses the basic pyrimidine structure. Aspartic acid might therefore act as a precursor of pyrimidines in 
nucleic acid synthesis and thus be required for zygote formation. Swenson (1950) showed that inhibition of the adaptive synthesis of galactozymase in yeasts by ultraviolet light (u.v.) was probably due to a primary effect on nucleic acid synthesis; Pollock (1953) reached a similar conclusion. Kelner (1953) subsequently showed that u.v.-irradiation specifically and rapidly inhibited deoxyribonucleic acid synthesis in Escherichia coli, yet treatment of donor strains of $\boldsymbol{E}$. coli $\mathrm{K}-12$ with small doses of u.v. light reduces their fertility little or not at all when the strains are mated immediately after u.v.-irradiation $($ Hayes, 1953 $b$ ). It seems, therefore, unlikely that deoxyribonucleic acid synthesis is an essential prerequisite of zygote formation in $E$. coli K-12. This conclusion is confirmed by the observation that 8-azaguanine had no effect on the recombination rate when used at concentrations which were inhibitory to growth.

It is difficult to accept suggestion (ii) above in view of the evidence presented in Fig. 1, which shows that aspartic acid alone did not stimulate the recombination rate. Moreover, substances other than aspartic acid can show the same activity in zygote formation. However, these substances might lead to the endogenous production of aspartic acid which might then be excreted.

Saz \& Krampitz (1954) concluded that the tricarboxylic acid cycle was fully functional in Escherichia coli, from their analysis of the distribution of ${ }^{14} \mathrm{C}$ derived from acetate-2-14 $\mathrm{C}$ among isolated intermediates of the tricarboxylic acid cycle. Repaske \& Wilson (1953), with extracts of Azotobacter agile, demonstrated the 'sparking effect'. This phenomenon is essentially the catalytic oxidation of acetate by a $\mathrm{C}_{4}$ dicarboxylic acid intermediate of the tricarboxylic acid cycle. It seems likely that this is the explanation of the results of experiments such as shown in Fig. 1 where it can be seen that the combined effect of glucose and aspartic acid on the recombination rate greatly exceeded the sum of their individual effects.

Johnson \& Cohn (1952) showed that the stimulation of total growth of Escherichia coli produced by the addition of fumarate or malate to a complete culture medium could not be produced by the addition of an equivalent amount of glucose. They suggested that the stimulation was due to increased amounts of free energy made available to the cells. Among the substances tested for their ability to stimulate the recombination rate only those known intermediates of the Krebs cycle, i.e. succinic, fumaric and malic acids or their immediate precursors, e.g. glutamic acid, were able to do so. At low $\mathrm{pH}$ values the activity of all the dicarboxylic acids in stimulating the recombination rate was identical. This effect of the $\mathrm{pH}$ value (Tables 2 and 6) may reflect the greater ease of penetration of the non-amino dicarboxylic acids into the cells at lower $\mathrm{pH}$ values (Moses, 1955). The results obtained by using metabolic inhibitors support to varying degrees the suggestion that it is the supply of energy made available by the oxidation of acetate via the tricarboxylic acid cycle which is essential for zygote formation.

I am indebted to Dr S. R. Elsden for the gift of a quantity of sodium monofluoroacetate and to Dr J. C. White for 8-azaguanine. I would like to express my thanks to Professor Lord Stamp for the facilities of the department made available 
to me, and to thank Dr W. Hayes for his extensive help and his enthusiasm at all stages of the work, which was carried out during the tenure of a financial grant made by the British Empire Cancer Campaign. Thanks are also due to Miss L. Nethercott for secretarial assistance. The work forms part of a Ph.D. thesis submitted to the University of London.

\section{REFERENCES}

Abelson, P. H., Bolton, E. T., Britten, R., Cowie, D. B. \& Roberts, R. B. (1953). Synthesis of the aspartic and glutamic families of amino acids in Escherichia coli. Proc. nat. Acad. Sci., Wash. 39, 1020.

AJL, S. J. \& KAMEN, M. (1950). Studies on mechanism of acetate oxidation by bacteria. Fed. Proc. 9, 143.

Buffa, P. \& Peters, R. A. (1949). The in vivo formation of citrate induced by fluoroacetate and its significance. J. Physiol. 110, 488.

Cavalu, L. L. (1950). La sessualita nei batteri. Boll. Ist. sieroter. Milano, 29, 281.

Cavalli, L. L., Lederberg, J. \& Lederberg, E. M. (1953). An infective factor controlling sex compatibility in Bacterium coli. J. gen. Microbiol. 8, 89.

ElsDen, S. R. (1954). Fourth Symposium of the Society for General Microbiology. Autotrophic Micro-organisms. Cambridge University Press.

HAYes, W. (1952). Recombination in Bacterium coli K-12: unidirectional transfer of genetic material. Nature, Lond. 169, 118.

Hayes, W. (1953a). Observations on a transmissible agent determining sexual differentiation in Bacterium coli. J. gen. Microbiol. 8, 72.

Hayes, W. (1953b). The mechanism of genetic recombination in Escherichia coli. Cold. Spr. Harb. Symp. quant. Biol. 18, 75.

Hayes, W. (1957). The kinetics of the mating process in Escherichia coli. J. gen. Microbiol. 16, 97.

Johnson, C. B. \& Corn, E. M. (1952). Effect of certain acids of the tricarboxylic acid cycle on the growth of Escherichia coli. J. Bact. 63, 735.

Kelner, A. (1953). Growth, respiration, nucleic acid synthesis in ultravioletirradiated and in photoreactivated Escherichia coli. J. Bact. 65, 252.

Lederberg, J. (1947). Gene recombination and linked segregations in Escherichia coli. Genetics, 32, 505.

LEDERBERG, J. (1950). The selection of genetic recombinations with bacterial growth inhibitors. J. Bact. 59, 211.

Lederberg, J., Cavalui, L. L. \& Lenerberg, E. M. (1952). Sex compatibility in Escherichia coli. Genetics, 37, 720.

Lederberg, J. \& Lederberg, E. M. (1952). Replica plating and indirect selection of bacterial mutants. J. Bact. 63, 399.

Lederberg, J., LederberG, E. M., Zinder, N. D. \& Lively, E. R. (1951). Recombination analysis of bacterial heredity. Cold. Spr. Harb. Symp. quant. Biol. 16, 413.

Lederberg, J. \& Tatum, E. L. (1946). Novel genotypes in mixed cultures of biochemical mutants of bacteria. Cold. Spr. Harb. Symp. quant. Biol. 11, 113.

Lichstein, H. C. \& Cohen, P. P. (1944). Transamination in bacteria. J. biol. Chem. $157,85$.

Liebecq, C. \& Peters, R. A. (1949). The toxicity of fluoroacetate and the tricarboxylic acid cycle. Biochem. biophys. Acta, 3, 215.

Loomis, W. F. \& Lrpmann, F. (1948). Reversible inhibition of the coupling between phosphorylation and oxidation. J. biol. Chem. 173, 807 .

Lotspeich, W. D., Peters, R. A. \& Wilson, T. H. (1952). The inhibition of aconitase by 'Inhibitor Fractions' isolated from tissues poisoned with fluoroacetate. Biochem. J. 51, 20.

Moses, V. (1955). Tricarboxylic acid cycle reactions in the fungus Zygorrhynchus moelleri. J. gen. Microbiol. 13, 235. 
NeLson, T. C. (1951). Kinetics of genetic recombination in Escherichia coli. Genetics $36,162$.

Newcombe, H. B. \& Nyноцм, M. H. (1950). Anomalous segregation in crosses of Escherichia coli. Amer. Nat. 84, 457.

Pollock, M. R. (1953). Adaptation in Micro-organisms. Third Symposium of the Society for General Microbiology. Cambridge University Press.

Quastel, J. H. \& Woolf, B. (1926). The equilibrium between L-aspartic acid, fumaric acid and ammonia in presence of resting bacteria. Biochem. J. 20, 545.

Reichard, P. (1954). The enzymatic synthesis of ureidosuccinic acid in rat liver mitochondria. Acta chem. scand. 8, 795.

Repaske, R. \& Wilson, P. W. (1953). Oxidation of intermediates of the tricarboxylic acid cycle by Azobacter agile. Proc. nat. Acad. Sci., Wash. 39, 225.

Roberts, R. B., Cowie, D. B., Britten, R. \& Abelson, P. H. (1953). The role of the tricarboxylic acid cycle in amino acid synthesis in Escherichia coli. Proc. nat. Acad. Sci., Wash. 39, 1013.

RothFELs, K. H. (1952). Gene linearity and negative interference in crosses of Escherichia coli. Genetics, 37, 297.

Saz, H. E. \& Krampitz, L. O. (1954). Acetic acid oxidation by Escherichia coli: evidence for the occurrence of a tricarboxylic acid cycle. J. Bact. 67, 419.

Skipper, H. E., Mitchell, J. H., Bennett, L. L., Newton, M. A., Simpson, L. \& Edison, M. (1951). Observations on inhibition of nucleic acid synthesis resulting from administration of nitrogen mustard, urethan, colchicine, 2,6diaminopurine, 8-azaguanine, potassium arsenite and cortisone. Cancer Res. $11,145$.

Swenson, P. A. (1950). The action spectrum of the inhibition of galactozymase production by ultraviolet light. Proc. nat. Acad. Sci., Wash. 36, 699.

Tatum, E. L. \& Lederberg, J. (1947). Gene recombination in the bacterium Escherichia coli. J. Bact. 53, 673.

TEPLY, L. J. (1949). Studies on the cyclophorase system XIV. Mechanism of action of 2,4-dinitrophenol. Arch. Biochem. Biophys. 24, 383.

Wisseman, C. L., Smadel, J. E., Hahn, F. E. \& Hopps, H. E. (1954). Mode of action of chloramphenicol. I. Action of chloramphenicol on assimilation of ammonia and on synthesis of proteins and nucleic acids in Escherichia coli. J. Bact. 67, 662.

Wollman, E., JACOB, F. \& HAYEs, W. (1956). Conjugation and genetic recombination in Escherichia coli K-12. Cold. Spr. Harb. Symp. quant. Biol. 21 (in the Press). 